\title{
RESISTANCE OF DE-AGGLOMERATED NANO SILICA CONCRETE TO CHLORIDE INGRESS
}

\begin{abstract}
The influence of both de-agglomerated and as received nano silica (NS) on chloride ingress resistivity was investigated. Nineteen OPC/NS concrete mixes with different NS contents $(0,1,2,3,4,5$, and $6 \%$ by mass of OPC) were prepared and then exposed to chlorides. Two types of water (magnetized water (MW) and Tap water (TW)) were used. Two cylinders of $75 \times 150 \mathrm{~mm}$ were prepared from each concrete mix for measuring chloride profile along the cover zone and depth of chloride penetration into the cover zone. Results of this study showed that all the examined NS replacement levels can enhance resistivity of chloride ingress of OPC concrete providing using MW and magnetic stirring (MS) together in concrete fabrication. Replacing 3\% cement by NS and using both MW and MS results in the most significant reduction in both $\%$ chloride penetration and $\%$ total chloride content as compared to normal control concrete.
\end{abstract}

KEYWORDS: Nano silica; Magnetized Water; Chloride Penetration; Chloride Profile; De-agglomeration.

\section{INTRODUCTION}

Durability is very important for any construction material, because it directly affects the economics, serviceability, and maintenance of the structure. The durability of concrete depends on various factors such as external environment, internal properties of the concrete $(\mathrm{w} / \mathrm{b}$, moisture content, etc.), and the type and quantity of constituent materials.

Because nearly all concrete deterioration processes are driven in some manner by the ingress of water and waterborne agents, such as chloride and sulfate ions, one way to minimize problems is to make the concrete less permeable by, for example, densifying the cementitious paste. This densification is achieved by using lower water-cementitious materials ratio (w/b) and supplementary cementitious materials (SCMs) [1].

Nowadays the micro-level does not provide enough insights into building materials. Therefore, all around the world, increasing amounts of research funding are being diverted

into the nanolevel, which is claimed to have tremendous potential for the future [2]. The fundamental processes that govern the properties of concrete are affected by the

Lecturer of Properties and Strength of Materials, Civil Eng. Dept, Faculty of Engineering, Beni-Suef University, Egypt.

Corresponding author. Beni-suef university, Egypt performance of the material on a nanoscale. The mechanical properties and the durability of concrete mainly depend on the gradual refining microstructure of the hardened cement paste and the gradually improving of the paste-aggregate interface zone (ITZ) [3].

One interesting material to study is nanosilica (NS) produced from silica sand. Previous research on concrete using nanosilica has pointed out that improved workability and strength of concrete or mortar are to be expected [4-6]. The use of nanosilica dan microsilica as partial replacement of cement have some advantageous effects on concrete performance [7]. Nano- $\mathrm{SiO}_{2}$ was also found to be more efficient in enhancing strength than silica fume [7]. NS can improve the performance of cement-based materials matrix through increased production of $\mathrm{CSH}$ gel due to pozzolanic reaction and reduced amount of $\mathrm{Ca}(\mathrm{OH})_{2}$. It can also act as micro and nano filler [4].

However, up to now, little attention has been directed towards signifying the role of NS on the various aspects in relation to the degradation processes of concrete when subjected to severe conditions such as resistivity to chloride ingress. Therefore, the present research aims to study impacts of both de-agglomerated and as received NS on the chloride ingress process inside concrete in terms of total chloride profile and penetration depth of OPC concrete.

\section{EXPERIMENTAL}

\subsection{Materials and Mix Proportions}

Local ordinary Portland cement (OPC) was utilized throughout the work. $\mathrm{SiO}_{2}$ nano particles with average particle size of $40 \mathrm{~nm}$ and $60 \mathrm{~m}^{2} / \mathrm{g}$ Blaine fineness were purchased from the nano-technology laboratory, Faculty of Science, Beni-Suief University, Egypt. The chemical analysis and surface areas of OPC and NS are listed in Table 1.

A clean siliceous natural sand complying with ASTM C33 was used. The sand has a specific gravity of 2.65 and a fineness modulus of 2.75. Coarse aggregates are crushed dolomite, with the maximum particle size of $19 \mathrm{~mm}$. A Polycarboxylate superplasticizer (SP), produced from SIKA company, with a relative density of 1.1 , was incorporated into all mixes.

Sodium chloride $(\mathrm{NaCl})$ was used as a source of chlorides ions. The purity of Sodium chloride was $99.9 \%$.

Two types of waters (Normal Tap Water (TW) and Magnetized water (MW)) were used. The strength of the magnet which is used in the present study was (1.2) Tesla. 
Proc. of the Fourth Intl. Conf. Advances in Civil, Structural and Mechanical Engineering- CSM 2016

Copyright (C) Institute of Research Engineers and Doctors, USA .All rights reserved.

ISBN: 978-1-63248-093-4 doi: 10.15224/ 978-1-63248-093-4-59

Table 1 Chemical analysis and surface areas of OPC and NS.

\begin{tabular}{|l|c|c|c|c|c|c|c|c|c|c|}
\hline & $\mathrm{SiO}_{2}$ & $\mathrm{Al}_{2} \mathrm{O}_{3}$ & $\mathrm{Fe}_{2} \mathrm{O}_{3}$ & $\mathrm{CaO}$ & $\mathrm{MgO}$ & $\mathrm{Na}_{2} \mathrm{O}$ & $\mathrm{K}_{2} \mathrm{O}$ & $\mathrm{SO}_{3}$ & LOI & $\begin{array}{c}\text { Surface } \\
\text { area, } \mathrm{m}^{2} / \mathrm{g}\end{array}$ \\
\hline $\mathrm{OPC}$ & 21.3 & 3.58 & 5.05 & 63.5 & 1.39 & 0.26 & 0.22 & 2.05 & 2.57 & 0.32 \\
\hline $\mathrm{NS}$ & 97.53 & - & - & - & - & 2.47 & - & - & - & 60 \\
\hline
\end{tabular}

The experimental program includes two main phases. In the first, a set of seven OPC concrete mixes made with different contents of NS $(0,1,2,3,4,5$, and $6 \%$ by weight of OPC) were mixed using tap water (TW) to investigate the effect of adding different percentages of as received NS on the total chloride profile and penetration depth of OPC concrete.

The second phase compares two proposed methods for deagglomeration of NS. Used de-agglomeration methods prior to application to concrete mix are: (a) stirring TW, NS, and SP for 5 min using a low speed magnetic stirrer and (b) stirring MW, NS, and SP using the same magnetic stirrer. Six OPC concrete mixes made with different contents of NS $(1,2,3,4,5$, and $6 \%$ by weight of OPC) were prepared using TW and six OPC concrete mixes with the same proportions were prepared using MW throughout this phase. Table 2 shows the proportions of the concrete mixtures.

Preparation of mixtures in the first phase (seven OPC/NS concrete mixes) was performed in the following sequence:

(a) Weighing components, (b) mixing the solid components inside a turn tilt mixer for $1 \mathrm{~min}$, (c) adding NS and SP into TW, (d) adding the solution to the mixer and (e) finally mechanical mixing for $3 \mathrm{~min}$.

To fabricate the mixtures of the second phase (six OPC/NS concrete mixes), SP is firstly mixed into MW in a mixer, and then NS is added and stirred using the magnetic stirrer, Fig. 1 shows the magnetic stirrer used in this research.

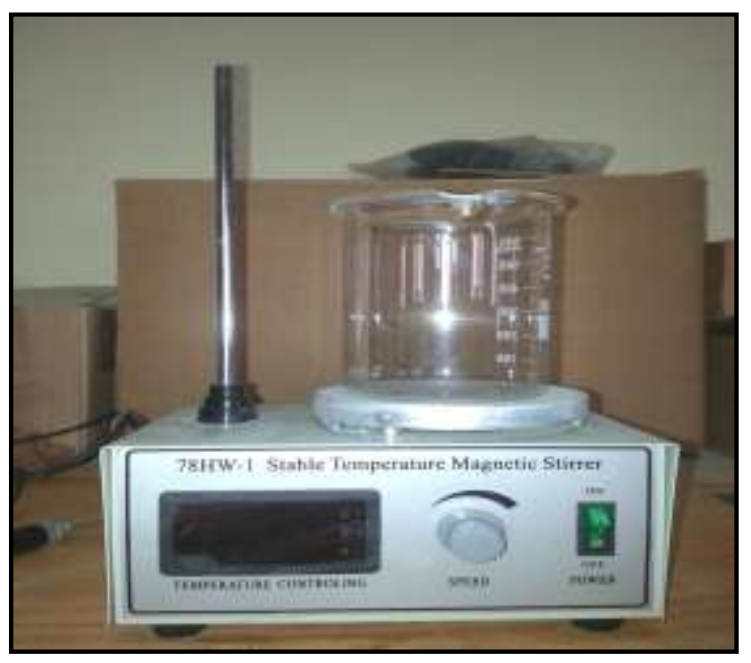

Fig. 1: Stable Temperature Magnetic Stirrer.
Coarse aggregate, sand and cement are mixed at a low speed for 2 minutes in a concrete centrifugal blender, then the mixture of MW, SP and NS are slowly poured in and stirred at a low speed for another 2 minutes to achieve proper workability. The same procedures of mixing were repeated again for the same concrete mixtures, but without using the magnetic stirrer.

Two cylinders of $75 \times 150 \mathrm{~mm}$ from each concrete mix were prepared for determining the total chloride profile and penetration depth measurements. After casting, all molded samples were covered with polyethylene sheet for 24 hours and then stored in water curing tanks for 27 days prior to exposing to the predetermined aggressive solutions. After curing, both upper and lower surfaces of the cylindrical concrete specimens prepared for total chloride profile and penetration measurements were coated with epoxy to achieve unidirectional flow, see Fig. 2. Once the epoxy dried, the cylinders were fully submerged in their specified aggressive solution containing 5\% sodium chloride for an exposure period of 10 months.

Each cylinder specified for chloride penetration was vertically cut into two half pieces. Both sawn and fracture surfaces were sprayed with $0.1 \mathrm{~N}$ silver nitrate solution indicator. After spraying silver nitrate solution, the color of the sprayed surface change due to the precipitation of white $\mathrm{AgCl}$ when the chloride ion is present. The depth of chloride penetration can be detected due to the lighter color compared to the unpenetrated material. The average of six measurements (three on each side of the spilting sample) was then considered. For all tests, triplicate specimens were used for each case of study and the average of results was then considered.

For determining total chloride profile, the specimens were cutted at various depths from the exposed surface to chloride using a lathe. The cutting processes were carried out at progressive depths up to $50 \mathrm{~mm}$ into the specimen from the surface which was exposed to chloride ions. The dust produced from cutting was sieved through a $150 \mu \mathrm{m}$ mesh to obtain a homogeneous sample. The samples were then kept in air tight plastic bags until testing. The prepared dust from different depths was analyzed for measuring the amount of total chloride content according to BS 1881: part 124, 1989. 
Proc. of the Fourth Intl. Conf. Advances in Civil, Structural and Mechanical Engineering- CSM 2016

Copyright (C) Institute of Research Engineers and Doctors, USA .All rights reserved.

ISBN: 978-1-63248-093-4 doi: 10.15224/ 978-1-63248-093-4-59

Table 2 Mixture proportions for cubic meter of OPC/NS concrete mixes

\begin{tabular}{|c|c|c|c|c|c|c|c|c|c|}
\hline \multirow{2}{*}{$\begin{array}{l}\text { Mix } \\
\text { code }\end{array}$} & \multirow{2}{*}{$\begin{array}{l}\mathrm{OPC} \\
(\mathrm{Kg})\end{array}$} & \multirow{2}{*}{$\begin{array}{c}\mathrm{NS} \\
(\mathrm{Kg})\end{array}$} & \multirow{2}{*}{$\begin{array}{c}\text { NS } \\
\text { w. } \%\end{array}$} & \multirow{2}{*}{$\begin{array}{c}\text { Water } \\
(\mathrm{Kg})\end{array}$} & \multirow{2}{*}{$\begin{array}{l}\mathrm{w} / \mathrm{b} \\
\text { ratio }\end{array}$} & \multicolumn{2}{|c|}{$\begin{array}{c}\text { Aggregate } \\
(\mathrm{Kg})\end{array}$} & \multirow{2}{*}{$\begin{array}{c}\text { SP } \\
(\mathrm{Kg})\end{array}$} & \multirow[t]{2}{*}{ Phase } \\
\hline & & & & & & Coarse & Fine & & \\
\hline Ref. & 440 & 0 & 0 & 198 & 0.45 & 1062 & 710 & 4.4 & \multirow{7}{*}{$\begin{array}{l}\text { (1) } \\
\text { TW }\end{array}$} \\
\hline M1 & 435.6 & 4.4 & 1 & 198 & 0.45 & 1062 & 710 & 4.4 & \\
\hline M2 & 431.2 & 8.8 & 2 & 198 & 0.45 & 1062 & 710 & 4.4 & \\
\hline M3 & 426.8 & 13.2 & 3 & 198 & 0.45 & 1062 & 710 & 4.4 & \\
\hline M4 & 422.4 & 17.6 & 4 & 198 & 0.45 & 1062 & 710 & 4.4 & \\
\hline M5 & 418 & 22 & 5 & 198 & 0.45 & 1062 & 710 & 4.4 & \\
\hline M6 & 413.6 & 26.4 & 6 & 198 & 0.45 & 1062 & 710 & 4.4 & \\
\hline M7 & 435.6 & 4.4 & 1 & 198 & 0.45 & 1062 & 710 & 4.4 & \multirow{6}{*}{$\begin{array}{c}(2) \\
\text { TW and } \\
\text { Magnetic } \\
\text { Stirring }\end{array}$} \\
\hline M8 & 431.2 & 8.8 & 2 & 198 & 0.45 & 1062 & 710 & 4.4 & \\
\hline M9 & 426.8 & 13.2 & 3 & 198 & 0.45 & 1062 & 710 & 4.4 & \\
\hline M10 & 422.4 & 17.6 & 4 & 198 & 0.45 & 1062 & 710 & 4.4 & \\
\hline M11 & 418 & 22 & 5 & 198 & 0.45 & 1062 & 710 & 4.4 & \\
\hline M12 & 413.6 & 26.4 & 6 & 198 & 0.45 & 1062 & 710 & 4.4 & \\
\hline M13 & 435.6 & 4.4 & 1 & 198 & 0.45 & 1062 & 710 & 4.4 & \multirow{6}{*}{$\begin{array}{c}(3) \\
\text { MW and } \\
\text { Magnetic } \\
\text { Stirring }\end{array}$} \\
\hline M14 & 431.2 & 8.8 & 2 & 198 & 0.45 & 1062 & 710 & 4.4 & \\
\hline M15 & 426.8 & 13.2 & 3 & 198 & 0.45 & 1062 & 710 & 4.4 & \\
\hline M16 & 422.4 & 17.6 & 4 & 198 & 0.45 & 1062 & 710 & 4.4 & \\
\hline M17 & 418 & 22 & 5 & 198 & 0.45 & 1062 & 710 & 4.4 & \\
\hline M18 & 413.6 & 26.4 & 6 & 198 & 0.45 & 1062 & 710 & 4.4 & \\
\hline
\end{tabular}

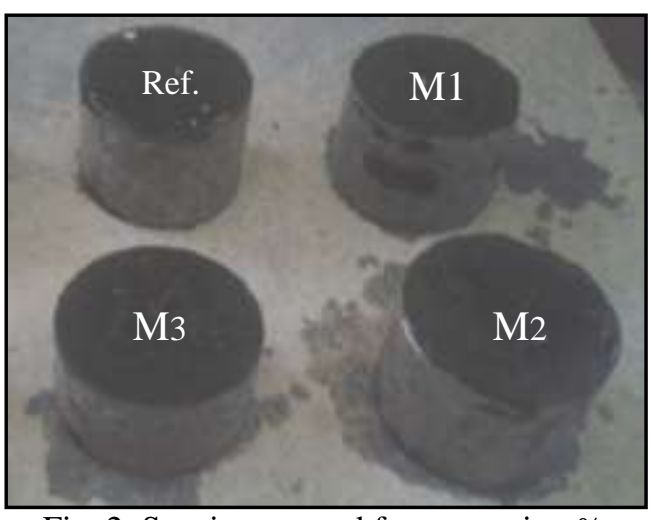

Fig. 2: Specimens used for measuring \% chloride penetration

\section{RESULTS AND DISCUSSION 3.1 Chloride penetration depth}

\subsubsection{Phase 1}

The effect of as received NS content on $\%$ chloride penetration of OPC/NS concrete mixes is demonstrated in Fig. 3. As seen, the increase of the substitution of OPC with as received NS up to $1 \%$, decreases $\%$ chloride penetration. This is attributed to the effect of NS, which behaves not only as a filler to improve microstructure, but also as an activator to promote pozzolanic reaction as well as acts as nucleating sites to form more accumulation and precipitation of calcium silicate, aluminate and alumino-silicate hydrates in the open pores originally filled with water, leading to the formation of homogeneous, dense and compact microstructure [8].

By increasing the NS content than $1 \%$, $\%$ chloride penetration of OPC/NS mixes increases. This increase can be attributed to the clear agglomeration in the -as received NS [9].

The amount of increase in $\%$ chloride penetration reaches about $5,10,13,18$, and $23 \%$, when $2,3,4,5$, and $6 \%$ NS replacement levels were adopted, respectively, compared to that of pure OPC concrete

\subsubsection{PHASE 2 (TW and MS)}

The effect of MS on \% chloride penetration of OPC/NS concrete mixes is also demonstrated in Fig. 3. It can be seen that, by increasing the substitution of OPC with NS up to $3 \%$, \% chloride penetration is significantly reduced. By increasing the NS content than $3 \%$, the reduction in $\%$ chloride penetration of OPC/NS mixes decreases but is still lower than that of the reference specimen, the amount of reduction in $\%$ chloride penetration reaches about $32,36,41$, 23,17 , and $23 \%$, when $1,2,3,4,5 \%$ NS replacement levels were adopted, respectively, compared to that of reference specimen. This can be attributed to the effect of magnetic stirring (MS) in de-agglomerating, and dispersing of nano particles.

Using of $6 \% \mathrm{NS}$ results in chloride penetration increase of $3 \%$ compared to that of the reference specimen. This is thought to be caused by the agglomeration effect. Because when the content of NS is large, nano particles are difficult 
Proc. of the Fourth Intl. Conf. Advances in Civil, Structural and Mechanical Engineering- CSM 2016

Copyright (C) Institute of Research Engineers and Doctors, USA .All rights reserved.

ISBN: 978-1-63248-093-4 doi: 10.15224/ 978-1-63248-093-4-59

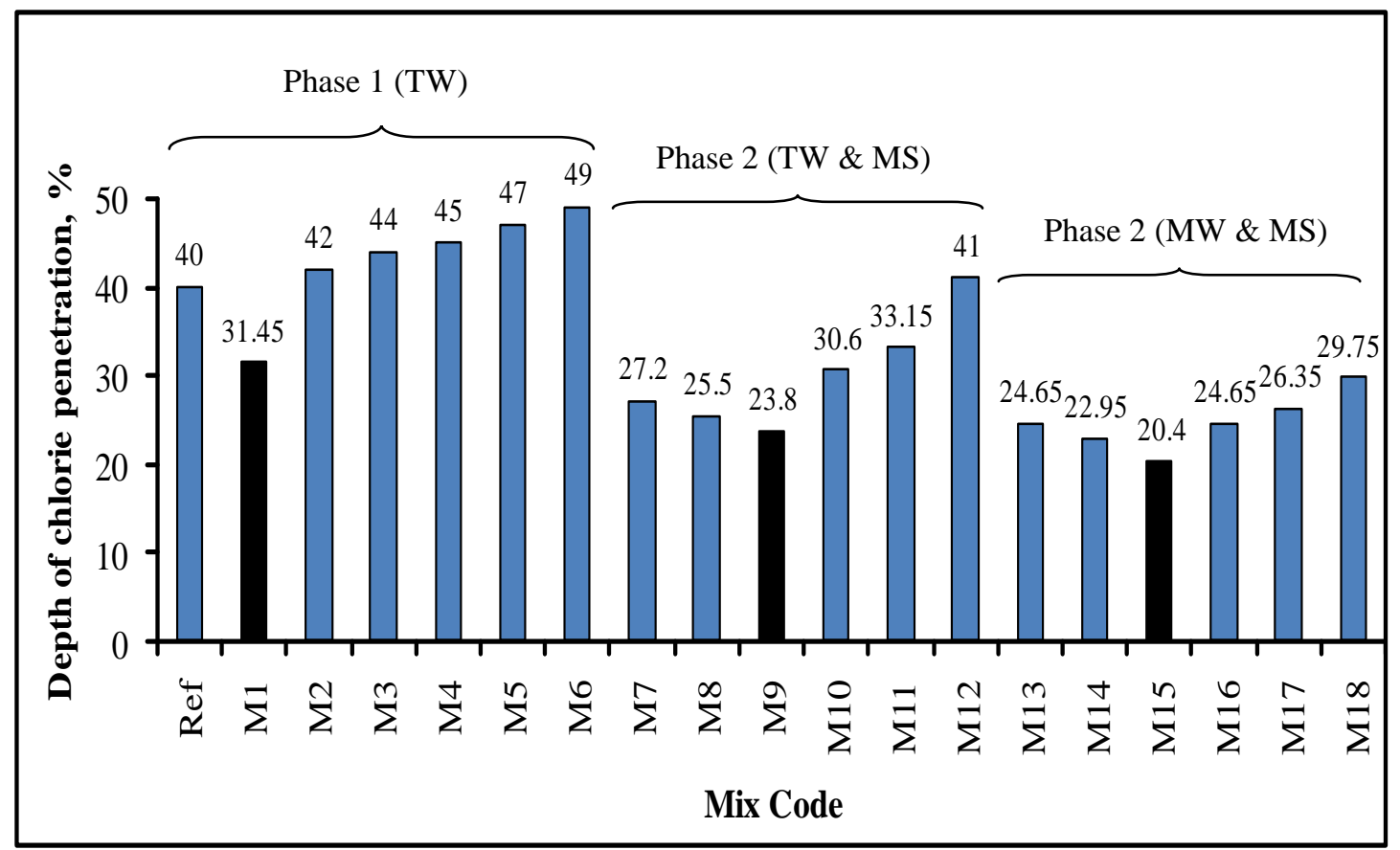

Fig. 3: \% Chloride penetration of concrete mixtures.

to disperse uniformly. Therefore, they create a weak zone in the form of voids, consequently the homogeneous hydrated microstructure cannot be formed and a lower strength will be probable [9].

\subsubsection{PHASE 2 (MW and MS)}

The effect of both MW and MS on the chloride penetration depth of OPC/NS concrete mixes is demonstrated in Fig. 3. As seen, $\%$ chloride penetration is significantly reduced with increasing NS content up to $3 \%$. By increasing the NS content than $3 \%$, the reduction in $\%$ chloride penetration of OPC/NS mixes decreases but is still lower than that of the reference specimen. The amount of reduction in $\%$ chloride penetration reaches about $38,43,49,38,34$, and $25 \%$, when $1,2,3,4,5$, and $6 \%$ NS replacement levels were considered, respectively, compared to that of the pure OPC concrete. This reduction can be attributed to the effect of both magnetized water magnetic stirring in de-agglomerating, and dispersing of nano particles.

\subsection{Chloride Profile}

Figure 4 demonstrates the total chloride profile of OPC concrete mixes of phase 2 (MW and MS). As seen, at all distances, \% total chloride content is significantly reduced with increasing NS content up to $3 \%$. By increasing the NS content than $3 \%$, the reduction in $\%$ total chloride content of OPC/NS mixes decreases but is still lower than that of the reference specimen. This reduction can be attributed to the effect of both magnetized water magnetic stirring in deagglomerating, and dispersing of nano particles.

Moreover, at all distances, the lowest \% total chloride content is obtained for the mix with $3 \%$ NS. Also, \% total chloride content of all studied specimens is significantly decreased with increasing the distance from the surface which exposed to chloride ions.

\section{CONCLUSIONS}

According to the experimental work carried out in this investigation, the main conclusions can be summarized as follow:

1. Replacing up to $1 \%$ cement by as received NS decreases $\%$ chloride penetration, while further replacements increases $\%$ chloride penetration.

2. It was confirmed that, using of MW and MS in concrete fabrication enhanced the resistance to chloride ingress of all examined mixes.

3. Replacing $3 \%$ cement by NS and using both MW and MW in concrete fabrication results in the most significant reduction in the total chloride content and \% chloride penetration as compared to normal control concrete. 
Proc. of the Fourth Intl. Conf. Advances in Civil, Structural and Mechanical Engineering- CSM 2016

Copyright (C) Institute of Research Engineers and Doctors, USA .All rights reserved.

ISBN: 978-1-63248-093-4 doi: 10.15224/ 978-1-63248-093-4-59

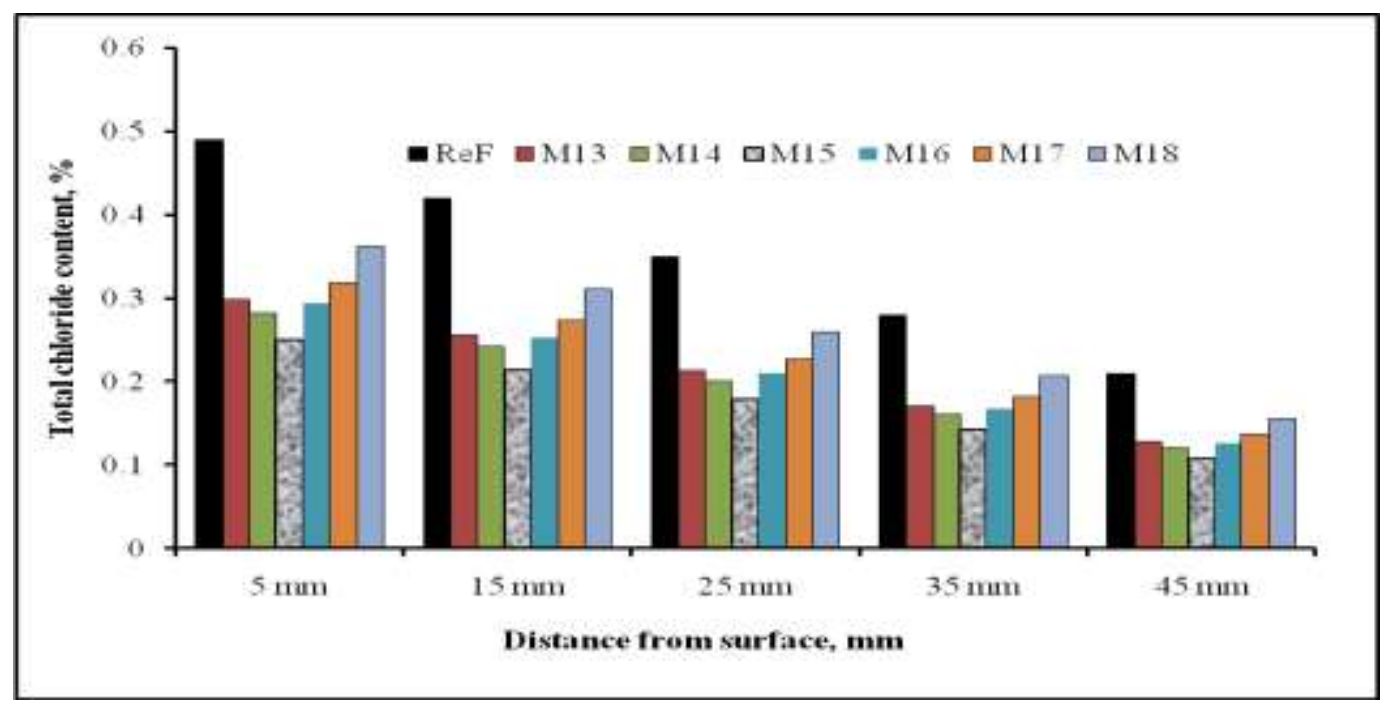

Fig. 4: Total chloride profile of OPC mortar made with different contents of NS.

\section{REFERENCES}

1. John, S., James, D., Paul, D. and Sharon L., "Guidelines for concrete mixtures containing supplementary cementitious materials to enhance durability of bridge decks", National Cooperative Highway Research Program, report 566, 2007.

2. Scrivener, K.L. and Kirkpatrick, R.J. "Innovation in use and research on cementitious material” , Cement and Concrete Research 38 (2008), pp. 128-136.

3. Nili, M., Ehsani, A. and Shabani, K. "Influence of nano- $\mathrm{SiO}_{2}$ and micro-silica on concrete performance ”, Proceedings Second International Conference on Sustainable Construction Materials and Technologies. June 28-30 (2010). Universita Ploitecnica delle Marche, Ancona, Italy, 2010.

4. Hosseini,P.,Mohamad,M.I.,Nekooie,M.A.,Taherkhani ,R.,Booshehrian,A, Toward Green Revolution in Concrete Industry: The Role of Nanotechnology ( A Review), Australian Journal of Basic and Applied Sciences, (2011), 5(12), p. 2768-2782.

5. Ji,T., "Preliminary Study on Water Permeability and Microstructure of Concrete Incorporating Nano- $\mathrm{SiO}_{2}$ ", Cement and Concrete Research, (2005), Vol. 35, p. 1943-1947.

6. Li, G., "Properties of High -Volume Fly Ash Concrete Incorporating $\mathrm{Nano}-\mathrm{SiO}_{2}$ ”, Cement and Concrete Research, (2004), Vol.34, p. 1043-1049.

7. Nili, M., Ehsani, A., Shabani,K., "Influence of nano$\mathrm{SiO}$ and Microsilica on Concrete Performance" , The university of Wisconsin milwauke centre for by product utilization, second international on sustainable construction Materials and Technologies, June, 28-30, (2010).
8. Heikal M, Abd El Aleem S, and Morsi W.M. (2013), "Characteristics of blended cements containing nano-silica” ,HBRC Journal, Vol. 9, pp. 243-250.

9. Li H., Xiao H.G., OU J.P. (2004), “A study on mechanical and pressure-sensitive properties of cement mortar with nanophase materials" , Cement and Concrete Research, Vol. 34, 435-438. 